\title{
THE DEVELOPMENT AND VALIDATION OF A CONCEPT MAPPING EMOTIONS SCALE (CM-ES) FOR UNIVERSITY STUDENTS
}

\author{
Xinyuan Li, Yanyan Duan, Tong Lu and Guoqing Zhao \\ School of Educational Technology, Faculty of Education, Beijing Normal University, Beijing, China
}

\begin{abstract}
Concept mapping is a practical approach to meaningful learning, and emotion is one of the most important factors that affect students' learning. However, few studies have focused on learners' emotions of concept mapping. This research aims to develop and verify a CM-ES and to investigate university students' emotions of concept mapping with the aid of this scale. A total of 88 freshmen participated in the study by attending a two-week thinking skills course provided by the researchers. The CM-ES translated and modified from the Academic Emotion Scale of Govaerts and Grégoire (2008) was used to collect the students' emotions of concept mapping. A five-dimensional scale, including frustration, anxiety, shame, enjoyment, and hope, was obtained through exploratory factor analysis, and Cronbach's reliability coefficient indicates good reliability and validity of CM-ES. The result shows that the emotion of the students' concept mapping is relatively positive. The development of the CM-ES provides the researchers and educators with an effective tool to measure the emotion of concept mapping and helps researchers understand students' emotions when using concept maps.
\end{abstract}

\section{KEYWORDS}

Concept Map, Emotion, CM-ES

\section{INTRODUCTION}

As a thinking visualization tool, concept maps (Novak, 1984) have similar functions to cognitive tools (Jonassen, 1992). They can help students focus on thinking tasks with a high cognitive load by reducing their low-level cognitive load (Jonassen, 1992; Lajoie and Derry, 1993). Many studies have shown that concept maps can promote students' critical thinking and other higher-order thinking skills (Hwang et al., 2020). Research also shows that concept maps have an impact on students' learning motivation and academic performance (Chiou, Tien and Tang, 2020). However, the concept map itself is an external tool for learners, and it may also bring the cognitive load to learners, thereby affecting students' emotions and willingness to use concept maps (Machado and Carvalho, 2020).

Emotion is one of the important factors that affect students' learning (Chiang and Liu, 2014); it can affect the important factors of students' self-system opening and closing. When the self-system is closed, the cognitive system and the metacognitive system are also difficult to function (Marzano and Kendall, 2006). Studies have shown that students' learning is deeply affected by emotions, which are related to specific learning situations and learning behaviors (Govaerts and Grégoire, 2008). Therefore, more and more researchers have begun to pay attention to the emotional experience of students in different learning situations.

However, research related to concept maps seldom pays attention to the emotions of students using concept maps to learn. Therefore, it is very necessary to understand students' emotions when they use concept maps to learn. This study intends to develop a Concept Mapping-Emotion Scale by revising the Student Academic Emotion Scale and tailoring it to the context of the concept mapping and test the reliability and validity of the scale. Compiling a scale to measure the application emotion of concept maps can not only help researchers understand the emotions of students in constructing concept mapping, but also provide a theoretical basis for the application of concept maps in teaching. 


\section{LITERATURE REVIEW}

\subsection{The Role of Concept Mapping in Instruction}

Concept maps are usually used as cognitive tools or evaluation tools in teaching. Research on concept maps as a cognitive tool mainly focuses on the impact of concept maps on student learning. For example, Hwang et al. (2020)found that the problem-producing method based on concept maps can improve students' academic performance, critical thinking tendency, and the quality of problem-producing. When the concept map is used as an evaluation tool, it usually includes the evaluation of the concept map and the evaluation of the students' knowledge construction through the concept map. For example, Cañas, Novak and Reiska (2015) elaborated the criteria and scoring method of a good concept map. In the study of Gracia-Moreno et al. (2017), the concept map was used as a tool to evaluate student learning in order to explore the use of private digital workspaces and public workspaces by French high school students.

However, concept maps are not useful in all situations, nor are they useful for all students. Immelman's (2018) research results show that concept mapping does not promote the conceptual understanding of South African accounting students. This is in contradiction with the research results that concept maps can promote the understanding of physics concepts in 10th-grade students (Farrokhnia et al., 2019). Conflicting research results suggest other factors that influence the application of concept maps, such as students' cognitive factors, emotions, and teaching methods. A study found that concept mapping has less effect on students with higher prior knowledge level, so the mastery of prior knowledge of students may be a factor that affects the use of concept maps. At the same time, the study also pointed out that the length of time that students use concept maps and their mastery of concept maps before experiments may have an impact on the promotion of concept maps to learning(Brandt et al., 2001).

The teaching method is also an important factor affecting concept mapping. Roessger, Daley and Hafez (2018) explore whether exercises, feedback, and relational frameworks help to improve students' concept mapping skills in the long term. The results of the research show that repeated practice and feedback improved the structural quality of students' concept maps, and also increased the number of autobiographical explanations in these concept maps. Furtado, Hirashima and Hayashi (2019) describe the Airmap interface, using automatic layout management and space separation to reduce the cognitive load in the concept mapping process, thereby improving the effectiveness of the concept map application.

Emotions and cognition in the learning process of students influence each other, and concept maps can be used as cognitive tools to assist students in learning, and emotion may be a factor that affects the application effect of concept mapping. The researcher pointed out that some students show a certain resistance to the concept map (Brandt et al., 2001). Because concept maps can promote meaningful learning for learners, and it is a difficult task to inspire students to change from rote learning practice to meaningful learning mode.

Many studies have studied the reasons that influence the application of concept maps from the perspective of cognition and teaching methods, but few studies have elaborated from the perspective of emotions, which may be due to the lack of tools for measuring the emotions of concept maps.

\subsection{The Influence of Emotion on Student Learning}

Emotions are people's psychological and behavioral responses to objective things (James, 1884; Cannon, 1987; Damasio, 2005). A large number of studies have shown that there is a close relationship between students' emotions and learning. For example, some scholars have found that positive emotions can improve the efficiency and effect of learning. In contrast, negative emotions can reduce the efficiency and effect of learning (Tauber et al., 2017). In this regard, the Dopamine Handbook explains that positive emotion will gradually increase the dopamine transmitter in the peripheral cortex. Transmitters can strengthen people's thinking flexibility to a large extent and enable people to have stronger response capabilities (Iversen et al., 2009).

It should be noted that due to different measurement methods, research methods, learning tasks, and other factors, the conclusions drawn from different studies may differ. Some research results show that positive emotions may not necessarily improve the effect of learning. For example, the experiment of Oaksford et al. (1996) found that neither positive nor negative emotions can interfere with certain reasoning. Other studies have found that happiness can promote simple reasoning, interfere with moderately difficult reasoning, and sadness can influence any reasoning. Interfering with difficult tasks, neutral emotions have a better effect on moderately difficult reasoning (Forgas, 1995). In addition, the specific context of emotions will also change the impact of emotions on learning (Götz et al., 2003). 


\subsection{Measurement of Emotions}

One of the research fields on emotion is the measurement of emotion. Emotion is a multi-dimensional structure and multi-component compound process, including internal experience, external expression, and physiological activation. Its manifestations are divided into explicit emotions and implicit emotions (Strongman, 2003). Commonly used self-reported measurement scales include ISO Project Mind Mirror Adjective List (MACL), Multiple Affective Adjective Checklist (MAACL), etc. But these scales do not reflect the emotional state of specific situations. The Academic Emotion Scale (AES) compiled by Govaerts and Grégoire (2008) contains six kinds of emotions related to academic work. Each emotion is represented by multiple items. The scale comprehensively measures multiple dimensions of emotion; the compilation process is standardized and has good reliability and validity. In this study, the academic emotion scale developed by Govaerts and Grégoire (2008) was Chineseized and adapted to form the CM-ES.

\subsection{The Present Study}

In the existing studies, the research on concept maps has focused on testing the validity of concept maps in different teaching situations, and concept maps are used to evaluate students' academic performance. Few studies have focused on students' emotions when using concept maps. Machado and Carvalho (2020) found that students' frustration with concept maps can be reduced by teachers' counseling or peer discussions. However, there is still a lack of scales that can comprehensively measure various emotional states of students when using concept maps.

Measuring students' emotions towards concept map tools can help teachers understand students' emotional experience in teaching practice, to make targeted interventions, thereby improving the effectiveness of teaching and students' learning experience. The purpose of this research is to develop a scale to measure the emotional state of concept mapping and to improve the research on the application of concept maps.

\section{METHOD}

\subsection{Research Context}

The purpose of this study was to develop the CM-ES and to investigate the emotional experiences of Chinese undergraduate students with concept maps when using them to solve problems.

The study was conducted at a Chinese university that offers a long-standing thinking course. That is a public elective course, so students of the course have different majors. In this course, students learn to use many thinking tools, such as Thinking Maps (Hyerle, 2011), Mind Map (Buzan and Buzan, 2010), and Concept Map (Novak, 1984). The course is delivered online by Dingding, which is an online education platform. In that platform, the teachers can arrange online meetings, and students can turn on the microphone to interact with the instructor at any time during class. In learning concept maps, the teacher first introduces the origin and usage of concept maps. Then the teacher demonstrates how to construct concept maps by CmapTools software.

\subsection{Participants}

A total of 88 college students from a college in China participated in this study. These students came from different majors, including physics, chemistry, history, and English, etc. Of all the participants, 86 completed the concept mapping task. For the CM-ES questionnaire, a total of 52 data were collected in this study, two of which were repeatedly completed by the same person, and the responses of which took less than one minute were deleted. Matching the concept mapping task and the CM-ES questionnaire, a total of 48 students completed the whole process, and the data were valid, with a valid response rate of $54.44 \% .14 .58 \%(n=7)$ of them are males and $85.42 \%(n=41)$ are females. All students were freshmen. 


\subsection{Data Collection and Analysis}

\subsubsection{Concept Map Task}

After students have a basic understanding of concept maps, students are required to create a concept map of the topic of their choice, such as figure 1, use the concept map to assist in analyzing the question and responding to the question (Novak and Cañas, 2006). Finally, they are required to submit their concept maps.

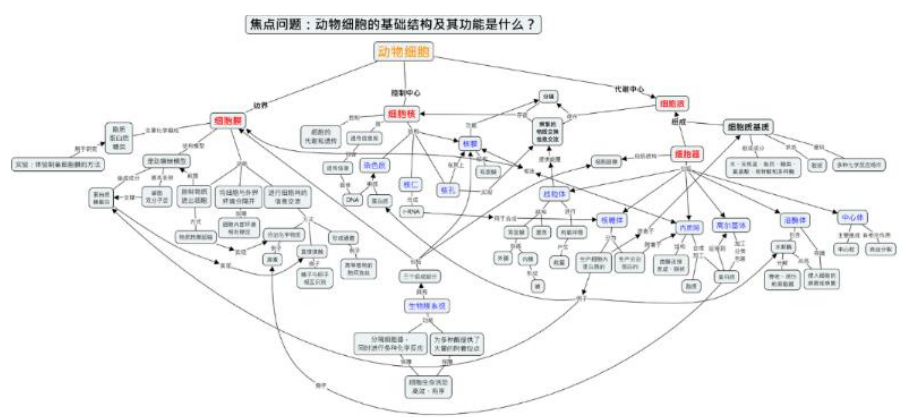

Figure 1. A concept map prepared by a student

\subsubsection{CM-ES}

Immediately after students completed the concept mapping task, they were given a digital version of the CM-ES questionnaire, also created by the Questionnaire Star tool, to investigate students' emotions about using the concept maps.

The questionnaire consisted of two parts. The first part of the questionnaire included questions asking for the participants' background information, including major and gender. In the second part of the questionnaire, a total of 26 items adapted from an English emotion scales proposed by Govaerts \& Grégoire (2008) were used to examine students' emotion.

The context we conducted the CM-ES is different from the initial scales we adapted investigated in the situation of a math exam preparation. Hence, all "math" words in the items were replaced with the "concept map". To distinguish from the original ones, we add the suffix "CM" to the name of every construct, which means the scales are constructed in the context of drawing concept maps. So, the final names of the six constructs are Frustration-CM, Anxiety-CM, Shame-CM, Enjoyment-CM, Hope-CM, and Pride-CM, respectively.

The initial CM-ES was designed to measure six components of emotions concerning the construction of concept maps, with six items for Frustration-CM, five items for Anxiety-CM, four items for Shame-CM, four items for Enjoyment-CM, four items for Hope-CM, and three items for Pride-CM. All items were designed on a seven-point Likert scale from 1 "I do not agree at all" to 7 " I totally agree". An educational technology specialist and three graduate students majoring in educational technology reviewed the items to improve the readability and content validity of the instrument.

\subsection{Data Analysis}

SPSS 25.0 was used to analyze the data. Firstly, exploratory factor analysis (EFA) was conducted with all original items to clarify the structure of the CM-ES, and Cronbach's alphas $(\alpha)$ were calculated to determine the internal consistency of each component of the CM-ES.

Secondly, a t-test was performed to examine the differences between students of different genders. Lastly, correlation analysis and stepwise regression were implemented to explore the prediction of Frustration-CM, Anxiety-CM, Shame-CM, Enjoyment-CM, Hope-CM, and Pride-CM, respectively on their CM-ES. 


\section{FINDINGS}

\subsection{Validation of the CM-ES}

Exploratory factor analysis with a varimax rotation was used to clarify the structure of the CM-ES survey. Through the first factor analysis (see Table 1), the initial items from Anxiety-CM construct, Hope-CM construct, Shame-CM construct, Enjoyment-CM construct, and Frustration-CM construct were all classified into the corresponding components as expected. However, one initial item from the Pride-CM construct was classified into the Hope-CM component, and the other two initial items from the Pride-CM construct were classified into the Enjoyment-CM component. Also, the items Frustration-CM4 and Enjoyment-CM1 were removed as these items did not fit the expected component. After removing these two items, factor analysis was conducted again with these 24 items.

The validated CM-ES questionnaire contains 24 items in the five new components: Anxiety-CM (five items); Hope-CM(five items); Shame-CM(four items); Enjoyment-CM(five items), and Frustration-CM (five items). a was computed to assess the questionnaire's reliability. Results showed that a of the total scale was .765, and a of each dimension( Anxiety-CM, Hope-CM, Shame-CM, Enjoyment-CM, and Frustration-CM) were $.900, .884, .908, .830$, and .859 , which suggested high reliability.

Table 1 . The first exploratory factor analysis

\begin{tabular}{|c|c|c|c|c|c|}
\hline \multirow[t]{2}{*}{ Item } & \multicolumn{5}{|c|}{ Factor component } \\
\hline & 1 & 2 & 3 & 4 & 5 \\
\hline Frustration5 & .760 & & & & \\
\hline Frustration2 & .711 & & & & \\
\hline Frustration1 & .702 & & & & \\
\hline Frustration3 & .699 & & & & \\
\hline Frustration6 & .673 & & & & \\
\hline Frustration4 & .637 & .546 & & & \\
\hline Anxiety 5 & & .810 & & & \\
\hline Anxiety2 & & .798 & & & \\
\hline Anxiety 1 & & .671 & & & \\
\hline Anxiety 3 & & .665 & & & \\
\hline Anxiety4 & & .603 & & & \\
\hline Hope 4 & & & .867 & & \\
\hline Hope2 & & & .789 & & \\
\hline Pride1 & & & .749 & & \\
\hline Hope1 & & & .747 & & \\
\hline Hope 3 & & & .661 & & \\
\hline Enjoyment3 & & & & .867 & \\
\hline Enjoyment 2 & & & & .789 & \\
\hline Enjoyment 4 & & & & .749 & \\
\hline Pride2 & & & & .747 & \\
\hline Pride 3 & & & & .661 & \\
\hline Enjoyment1 & & -.517 & & .523 & \\
\hline Shame1 & & & & & .893 \\
\hline Shame2 & & & & & .887 \\
\hline Shame3 & & & & & .886 \\
\hline Shame4 & & & & & .796 \\
\hline
\end{tabular}

\subsection{Students' Scores on the CM-ES}

The means and standard deviations of the participants' scores on Anxiety-CM, Hope-CM, Shame-CM, Enjoyment-CM, and Frustration-CM were provided in Table 2. It's easy to find that students had positive emotions about using concept maps to solve problems. The mean scores for all the dimensions of positive emotions were above three, the mean scores for the frustration and anxiety dimensions of negative emotions were below three, and the mean score for the shame dimension was 3.16, which was slightly above three. 
Table 2. Descriptive statistics of CM-ES

\begin{tabular}{llll}
\hline Item & $\mathrm{N}$ & Mean & S.D. \\
\hline Frustration-CM & 48 & 2.52 & 0.24 \\
Anxiety-CM & 48 & 2.43 & 0.30 \\
Shame-CM & 48 & 3.16 & 0.21 \\
Enjoyment-CM & 48 & 3.48 & 0.19 \\
Hope-CM & 48 & 3.22 & 0.27 \\
\hline
\end{tabular}

\subsection{Gender Differences in the CM-ES}

As presented in Table 3, five emotions showed gender differences. No significant mean differences were detected. However, male students reported more frustration and hope, but less shame than female students.

Table 3. Gender differences of CM-ES

\begin{tabular}{lllllll}
\hline \multirow{2}{*}{ Emotions } & Male & \multicolumn{3}{c}{ Female } & t & \multirow{2}{*}{ Sig. } \\
\cline { 2 - 6 } & Mean & S.D. & Mean & S.D. & 0.80 & 0.43 \\
Frustration & 2.71 & 0.55 & 2.48 & 0.73 & -0.02 & 0.99 \\
Anxiety & 2.43 & 0.57 & 2.43 & 0.76 & -1.14 & 0.26 \\
Shame & 2.79 & 0.59 & 3.22 & 0.97 & -0.23 & 0.82 \\
Enjoyment & 3.43 & 0.68 & 3.48 & 0.57 & 0.73 & 0.47 \\
Hope & 3.37 & 0.52 & 3.19 & 0.62 & & \\
\hline
\end{tabular}

\section{DISCUSSION}

This study developed and validated a five-dimensional CM-ES to measure students' emotions about concept maps when using concept maps to analyze problems. The results of the study showed that students had positive emotions on concept mapping, and there were no significant differences between students of different genders on each dimension of the CM-ES.

\subsection{Instrument Validation of the CM-ES}

In this study, the original PRIDE dimension of the CM-ES was eliminated, ultimately presenting five dimensions of the CM-ES. Two of the items in the Pride dimension were classified as enjoyment, and one was classified as hope. This is inconsistent with the findings of Govaerts and Grégoire (2008) for two possible reasons, firstly, the Pride dimension itself has a smaller number of items of only three compared to the other dimensions, and secondly, Pride, Enjoyment, and Hope are all positive emotions, and different people may interpret and feel emotions differently, and this perception of emotions is influenced by the sample (Terracciano et al., 2003). Thus, it is not uncommon for emotions containing intrinsic associations to be clustered under the same factor in studies related to academic emotions.

\subsection{The Emotional State of Freshmen while Concept Mapping}

From the results of the study, students had positive emotions about using concept maps to solve problems. This shows that students do not reject the use of concept maps to solve problems and have a positive attitude towards the results of using concept maps. The frustration and anxiety levels of students using concept maps are relatively low. This may be because the teacher instructs students to learn enough knowledge and skills to draw concept maps before completing tasks (Brandt et al., 2001). This also indicates that although concept maps can aid cognition, there is still a need to train users in basic knowledge before using them to reduce their negative emotions when using them. 
The present study also found no significant difference between male and female students' emotions towards the use of concept maps to solve problems. Whereas, Chiang and Liu (2014) found that male students in the college student sample experienced stronger emotions during science learning than female students, which is inconsistent with the results of the present study. The reason for this phenomenon is that the sample size of this study was small, with only seven male students, and the sample may have been underrepresented.

\subsection{Implications for Practice}

The results of this research show that college students' emotions when using concept maps are positive. Therefore, university teachers can use concept maps to teach complex concepts. At the same time, this research suggests that students should first learn about concept maps before using them. This can effectively reduce students' negative emotions towards concept maps. When teachers use concept maps for teaching, they can use the scale developed in this research to measure students' emotions, and then adjust the subsequent teaching strategies using concept maps according to students' emotions, and provide students with necessary scaffolding so that students can make better use of concept maps for learning.

\section{CONCLUSION}

This research has developed and verified a five-construct CM-ES. The five dimensions are confusion, anxiety, shame, enjoyment, and hope, which are used to measure students' emotions of concept mapping. The results of the study show that students have an overall positive attitude toward concept mapping. Therefore, it is recommended that teachers use concept maps in the teaching process of complex concepts. However, students need to be trained in concept mapping before using them, and teachers need to pay attention to students' emotions during concept mapping. Teachers can use the scale developed in this research to investigate the emotions of students after concept mapping to provide a basis for the next use of the concept map.

However, this study has some limitations as followed. The first limitation of this study is the small sample and the low proportion of male students, so the perception of emotions may be biased by the sample. In future studies, a larger sample size can be used to improve the validity of the questionnaire developed in this study, and further research can be conducted on the effect of emotions on applying concept maps in instructional activities. Also, the emotions measured in this study were static, whereas emotions change dynamically during the students' learning process, and future research could also be conducted with AI to dynamically identify the students' emotions when using concept maps to improve further the research related to the effect of emotions on the use of concept maps.

\section{REFERENCES}

Brandt, L. et al, 2001. 'The Impact of Concept-Mapping and Visualization on the Learning of Secondary School Chemistry Students', International Journal of Science Education, 23(12), pp. 1303-13.

Buzan, T. and Buzan, B., 2010. The Mind Map Book: Unlock Your Creativity, Boost Your Memory, Change Your Life. 1st edn. Edited by J. Harrison. New York, NY: Pearson Education Ltd.

Cañas, A. J., Novak, J. D. and Reiska, P., 2015. 'How good is my concept map? Am I a good Cmapper?', Knowledge Management \& E-Learning: An International Journal, 7(1), pp. 6-19.

Cannon, W. B., 1987 'The James-Lange theory of emotions: a critical examination and an alternative theory. By Walter B. Cannon, 1927', The American Journal of Psychology, 100(3-4), pp. 567-586.

Chiang, W.-W. and Liu, C.-J., 2014. 'Scale of Academic Emotion in Science Education: Development and Validation', International Journal of Science Education, 36(6), pp. 908-928. doi: 10.1080/09500693.2013.830233.

Chiou, C.-C., Tien, L.-C. and Tang, Y.-C., 2020. 'Applying structured computer-assisted collaborative concept mapping to flipped classroom for hospitality accounting', Journal of Hospitality, Leisure, Sport \& Tourism Education, 26, p. 100243. doi: 10.1016/j.jhlste.2020.100243.

Damasio, A., 2005. Descartes' Error: Emotion, Reason, and the Human Brain. Reprint. London: Penguin Books. 
Farrokhnia, M. et al., 2019. 'Computer-supported collaborative concept mapping: The effects of different instructional designs on conceptual understanding and knowledge co-construction', Computers \& Education, 142, p. 103640. doi: 10.1016/j.compedu.2019.103640.

Forgas, J. P., 1995. 'Mood and judgment: The affect infusion model (AIM)', Psychological Bulletin, 117(1), pp. 39-66. doi: 10.1037/0033-2909.117.1.39.

Furtado, P. G. F., Hirashima, T. and Hayashi, Y., 2019. 'Reducing Cognitive Load During Closed Concept Map Construction and Consequences on Reading Comprehension and Retention', IEEE Transactions on Learning Technologies, 12(3), pp. 402-412. doi: 10.1109/TLT.2018.2861744.

Götz, T. et al., 2003. Emotions, learning and achievement from an educational-psychological perspective, pp. 9-28. Available at: https://kops.uni-konstanz.de/handle/123456789/13904 (Accessed: 21 August 2020).

Govaerts, S. and Grégoire, J., 2008. 'Development and Construct Validation of an Academic Emotions Scale', International Journal of Testing, 8(1), pp. 34-54. doi: 10.1080/15305050701808649.

Gracia-Moreno, C. et al., 2017. 'Collaborative Knowledge Building Through Simultaneous Private and Public Workspaces', in Lavoué, É. et al. (eds) Data Driven Approaches in Digital Education. Cham: Springer International Publishing (Lecture Notes in Computer Science), pp. 553-556. doi: 10.1007/978-3-319-66610-5_61.

Hwang, G.-J. et al., 2020. 'Effects of a concept mapping-based problem-posing approach on students' learning achievements and critical thinking tendency: An application in Classical Chinese learning contexts', British Journal of Educational Technology, n/a(n/a). doi: 10.1111/bjet.13007.

Hyerle, D. N., 2011. Student Successes With Thinking Maps®: School-Based Research, Results, and Models for Achievement Using Visual Tools. Second. Thousand Oaks, Calif: Corwin.

Immelman, S., 2018. Concept mapping as a technique for scaffolding concept literacy in accounting: The case of an extended programme. Dissertation. University of Pretoria. Available at: https://repository.up.ac.za/handle/2263/68033 (Accessed: 20 August 2020).

Iversen, L. et al., 2009. Dopamine Handbook. 1e edn. Oxford; New York: Oxford University Press.

James, W., 1884. 'WHAT IS AN EMOTION?', Mind, os-IX(34), pp. 188-205. doi: 10.1093/mind/os-IX.34.188.

Jonassen, D. H., 1992. 'What are Cognitive Tools?', in Kommers, P. A. M. et al. (eds) Cognitive Tools for Learning. Berlin, Heidelberg: Springer (NATO ASI Series), pp. 1-6. doi: 10.1007/978-3-642-77222-1_1.

Lajoie, S. P. and Derry, S. J., 1993. Computers as Cognitive Tools. Lawrence Erlbaum Associates, 365 Broadway, Hillsdale, NJ 07642 (paperback: ISBN-0-8058-1082-X, \$32.

Machado, C. T. and Carvalho, A. A., 2020. 'Concept Mapping: Benefits and Challenges in Higher Education', The Journal of Continuing Higher Education, 68(1), pp. 38-53. doi: 10.1080/07377363.2020.1712579.

Marzano, R. J. and Kendall, J. S., 2006. The New Taxonomy of Educational Objectives, Corwin Press. Corwin Press, A SAGE Publications Company.

Novak, J., 1984. Learning How to Learn. 1st edn. Cambridge Cambridgeshire ; New York: Cambridge University Press.

Novak, J. D. and Cañas, A. J., 2006. 'The Theory Underlying Concept Maps and How to Construct and Use Them', Florida Institute for Human and Machine Cognition, 1(1), pp. 1-31.

Oaksford, M. et al., 1996. 'Mood, reasoning, and central executive processes', Journal of Experimental Psychology: Learning, Memory, and Cognition, 22(2), pp. 476-492. doi: 10.1037/0278-7393.22.2.476.

Roessger, K. M., Daley, B. J. and Hafez, D. A., 2018. 'Effects of teaching concept mapping using practice, feedback, and relational framing', Learning and Instruction, 54, pp. 11-21. doi: 10.1016/j.learninstruc.2018.01.011.

Strongman, K. T., 2003. The Psychology of Emotion: From Everyday Life to Theory. 5th edn. Chichester, West Sussex, England: Wiley.

Tauber, S. K. et al., 2017. 'The effects of emotion on younger and older adults' monitoring of learning', Neuropsychology, development, and cognition. Section B, Aging, neuropsychology and cognition, 24(5), pp. 555-574. doi: 10.1080/13825585.2016.1227423.

Terracciano, A. et al., 2003. 'Individual Difference Variables, Affective Differentiation, and the Structures of Affect', Journal of personality, 71(5), pp. 669-703. 